\title{
Comparison of Rare Earth Refinement in 4130 and HY100
}

\author{
Robert Tuttle (D)
}

check for

updates

Citation: Tuttle, R. Comparison of Rare Earth Refinement in 4130 and HY100. Metals 2021, 11, 540. https://doi.org/10.3390/ met11040540

Academic Editor: Filippo Berto

Received: 25 February 2021

Accepted: 23 March 2021

Published: 26 March 2021

Publisher's Note: MDPI stays neutral with regard to jurisdictional claims in published maps and institutional affiliations.

Copyright: (C) 2021 by the author. Licensee MDPI, Basel, Switzerland. This article is an open access article distributed under the terms and conditions of the Creative Commons Attribution (CC BY) license (https:/ / creativecommons.org/licenses/by/ $4.0 /)$.
Mechanical Engineering Department, Saginaw Valley State University, University Center, Saginaw, MI 48710, USA; rtuttle@svsu.edu

\begin{abstract}
Solidification based grain refinement has gained wide interest by both researchers and industry. This method provides a route for refinement in processes where thermomechanical approaches are ineffective. Prior research into 4130 and HY100 found very different responses when rare earth additions were made. The 4130 was effectively refined while HY100 showed no response. The cause of this difference was not determined. The research presented in this paper examined heats of 4130 and HY100 with rare earth silicide or EGR additions. Characterization included macrostructure examination, mechanical testing, thermal analysis, and electron microscopy. Refinement was observed only in the treated 4130 heats and corresponded to an increase in the peritectic temperature. The HY100 heats had no changes in macrostructure or solidification reactions. Rare earth containing inclusions of similar compositions were observed in the treated 4130 and HY100 heats. These inclusions appear to be a good fit for austenite based on the 4130 data. It was proposed that the unresponsiveness of HY100 was due to the strong segregation of nickel before the peritectic in that alloy. Nickel promotes austenite, and its segregation may provide a stronger driving force for its formation than the energy barrier reduction caused by the presence of rare earth inclusions.
\end{abstract}

Keywords: solidification; grain refinement; thermal analysis; rare earth

\section{Introduction}

Industrial needs create a continual drive for improving the strength and ductility of low alloy steels. Considerable research effort focuses on new steel alloys, but existing ones must also be improved. Obtaining improvements in strength and ductility at the same time limit the strengthening strategies available to reducing grain size. Several approaches can be employed limiting grain size: slight alloying element modifications for creating grain pinning precipitates, improved thermomechanical processing, and better nucleation during solidification [1]. Grain pinning and improved thermomechanical processing have been extensively examined but are of minimal use in net shape casting applications. Mechanical deformation of the steel in this application is not possible. Thus, manipulating the nucleation potential of the melt during solidification remains the most logical route.

Improving nucleation within a melt requires the addition of heterogeneous nuclei. These nuclei are solid particles in the liquid metal that assist the formation of the solid phase during freezing. The introduction of a large number of these particles will increase the number of dendrites formed during solidification and decrease the primary dendrite arm spacing (DAS). A smaller DAS will increase the strength and ductility of the alloy. Effective heterogeneous nuclei meet four criteria: solid at the freezing temperature of the alloy, thermodynamically stable in the melt, have a low lattice disregistry with the solid being formed, and wetted by the liquid metal [2]. Classical heterogeneous nucleation theory has implied that the lattice disregistry can only be between similar crystallographic structures; however, recently edge-to-edge theory has begun to extend this to any set of crystal structures for solidification and solid phase transformations [3-5]. Edge-toedge theory simply requires that a sufficient number of atoms share similar locations and distances on any set of crystallographic planes [4]. 
Rare earth (RE) additions have been found to result in the refinement of multiple steel alloys [6-12]. Most RE compounds, such as $\mathrm{Ce}_{2} \mathrm{O}_{3}$ and $\mathrm{CeAlO}_{3}$, have an excellent match with austenite, which tends to be the primary phase for high carbon steels and some stainless steels. A smaller set of compounds ( $\mathrm{CeS}$ and $\mathrm{CeO}$ ) match $\delta$-ferrite, the primary phase for most steels. Experimental evidence makes it clear RE additions are effective in all steels [6-12]. However, work by Tuttle showed that steels with higher portions of their freezing range dominated by austenite experienced more refinement of the solidification structure and final microstructure [13]. This result supports the conclusion that RE compounds tend to provide better nucleation for austenite than $\delta$-ferrite. However, the strong experimental evidence still supports some role for RE compounds in assisting $\delta$-ferrite formation since refinement does occur.

Initially, RE based grain refinement focused on single phase or non-hardenable steels [6,14-17]. This was due to the limited strengthening options of these alloys. However, interest also turned to low alloy steels $[11,12,18]$. Experimentation on 4130 found refinement occurred in the solidification structure which resulted in improved strength and ductility [11]. A larger strength increase was found in the quench and tempered (Q\&T) condition [11]. RE compounds produced a similar result in 1030 in the Q\&T condition [12]. However, this trend of refinement of the as-cast and Q\&T microstructures has not been universal. Work on HY100 uncovered no refinement in the as-cast structure but an improvement in the properties for the Q\&T condition [18]. It appears the RE inclusions may act as heterogeneous nuclei for austenite during the austenization stage of the Q\&T heat treatment. The nucleation of more austenite during heat treatment would lead to a smaller martensite packet size and the observed property improvements [11,12,18]. However, the lack of response by HY100 in the as-cast structure was not explained.

Most studies on grain refinement have primarily employed microscopy of the room temperature structure while others have included mechanical properties as well. Using only these techniques provides a limited view of how solidification of the sample progressed. It also requires considerable interpretation by the researcher. Direct observation of solidification would provide better data for determining the role of RE compounds. High temperature microscopy or X-ray diffraction (XRD) are not possible at steelmaking temperatures. However, thermal analysis can provide solidification reaction temperature data for illuminating the underlying mechanisms. Differential scanning calorimetry (DSC) has been used on steel alloys with limited success [19-23]. Metal samples tend to produce very small reaction signals in DSC equipment which makes identifying the reactions error prone [19-22]. NIST guidance on the DSC technique outlines that metal solidification is inherently difficult with this technique and that determination of the peritectic reaction may be impossible in most metal alloy systems [24]. Single thermocouple thermal analysis (TA) has been effectively applied to many metal systems and recently to steels as well [25-29]. Binczyk et al. performed work with a super alloy that compared the ability of TA with DSC [27]. These authors discovered that the solidification reactions were completely missed by DSC while the TA system easily detected all reactions [27]. Abraham et al. recently applied a modified TA technique to examine the effect of various alloy additions on the peritectic reaction in a plain carbon steel [29]. These results were used to verify predictions from existing equations on the presence of the peritectic reaction. The TA technique was used to avoid sample segregation issues and easily detect the peritectic [29]. Recent work by the author has found TA systems are easily able to measure solidification reactions in a range of alloys [26,30-34].

The purpose of this work was to compare the rare earth grain refinement response of 4130 and HY100. This comparison in behavior should provide insight into why some low alloys such as HY100 do not refine while others like 4130 do. Some of the data from the 4130 heats were published in a separate paper that provides some more detail [35]. The HY100 experimental data are unique. These heats were characterized using optical and electron microscopy, mechanical properties, and thermal analysis. Particular emphasis was placed on comparing the thermal analysis and solidification changes that rare earth 
additions made in these two alloys. The comparison helps develop a better understanding of how rare earth-based refinement occurs in low alloy steels.

\section{Materials and Methods}

The test castings consisted of two ASTM A781-05 style keel blocks per heat (Figure 1). Molds were manually compacted from a green sand composed of silica sand with a 35 AFS GFN, 7.5 wt. \% sodium bentonite clay, and 2.2 wt. \% water.

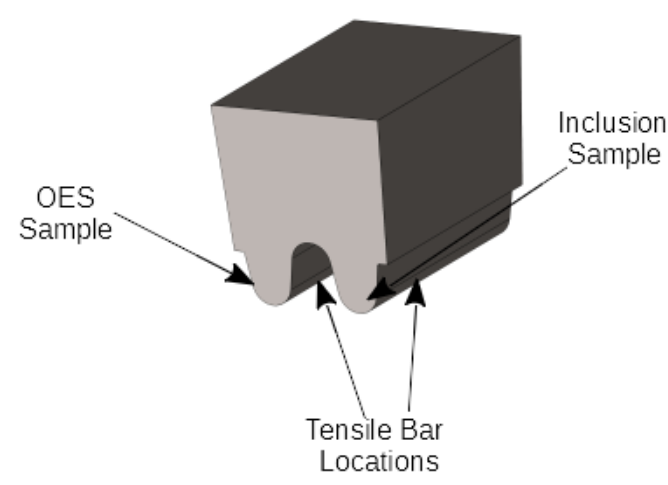

Figure 1. Experimental Casting.

A $3 \mathrm{kHz}$ induction furnace melted $23 \mathrm{~kg}$ heats of 4130 or HY100 under an air atmosphere. 1010 steel punchings, FeCr (69 wt. \% Cr, 5 wt. \% C, 1 wt. \% Si, 0.01 wt. \% P, 0.05 wt. \% S), FeMo (64 wt. \% Mo, 0.9 wt. \% Si, 0.3 wt. \% Cu, 0.03 wt \% P, 0.1 wt. \% S, 0.07 wt. $\%$ C), and nickel pellets $(99.98 \% \mathrm{Ni}, 0.007$ wt. $\%$ C) comprised the initial charge. Once the melt reached $1650{ }^{\circ} \mathrm{CC}$, FeSi (76 wt. \% Si, 1 wt. \% Al, 1 wt. \% Ca), FeMn (76 wt. \% Mn, 7 wt. \% C, 0.5 wt. \% Si, 0.2 wt. \% P, 0.01 wt. \% S), and graphite were added as needed to make each steel grade. Tapping happened at $1700{ }^{\circ} \mathrm{C}$ where aluminum shot and either no addition, 0.3 wt. \% RE silicide (18 wt. \% Ce, 11 wt. \% La, 53 wt. \% Si, 1 wt. \% Al, 3 wt. \% Ca, 0.07 wt. \% Ti), or 0.3 wt. \% EGR (20 wt. \% Cr, 20 wt. \% Si, $15 \mathrm{wt}$ \% Ce) were added into a magnesia fiber refractory lined ladle. (EGR is a commercially available cerium-based grain refiner for stainless steels.) After the additions, a small portion of the heat was transferred into a $2.5 \mathrm{~kg}$ capacity hand ladle. The contents were immediately poured into a TA cup. After cooling to $1590^{\circ} \mathrm{C}$, the ladle poured the keel block molds. The molds were allowed to cool for $25 \mathrm{~min}$ before being shaken out and continuing to cool to room temperature.

The TA system employed consisted of a shell core cup with an S-type thermocouple (TA cup), data acquisition system (DAQ), and computer software. Figure 2 depicts a typical TA cup. The software was originally designed for aluminum and cast iron alloys, but it has been modified for steels. The existing data smoothing up to fifth order differentiation, liquids detection, and solidus detection algorithms were used. Other peaks such as the peritectic had to be manually processed. Data acquisition occurred once the TA cup heated to $1050{ }^{\circ} \mathrm{C}$ and proceeded at a sampling rate of $38.4 \mathrm{~Hz}$ until it finally cooled to $1200{ }^{\circ} \mathrm{C}$.

Various samples were extracted from the test castings. Initial sectioning employed a bandsaw. Figure 1 depicts the locations for the optical emission spectroscopy (OES) sample, tensile bars, and inclusion samples. The TA cups were sectioned $20 \mathrm{~mm}$ from the bottom. The tensile bars were turned on a CNC lathe to create a $12.7 \mathrm{~mm}(0.5 \mathrm{inch})$ diameter tensile bar in accordance with ASTM E8-04. HY100 tensile bars were quench and tempered by austenitizing at $900{ }^{\circ} \mathrm{C}$ for one $\mathrm{h}$, water quenching, and tempering for two $\mathrm{h}$ at $625^{\circ} \mathrm{C}$. This was done since the alloy is only used in this condition. The 4130 samples were as-cast. A $500 \mathrm{kN}$ MTS hydraulic universal testing frame pulled the tensile bars at a strain rate of 0.01 1/min as per ASTM E8-04. Three tensile bars were pulled per heat. OES samples were ground and then analyzed with an Angstrom PolySpek spectrometer (Belleville, MI, USA) which has been specially calibrated for cerium in steel matrices. Table 1 lists the average composition for the three heats poured per alloy. 


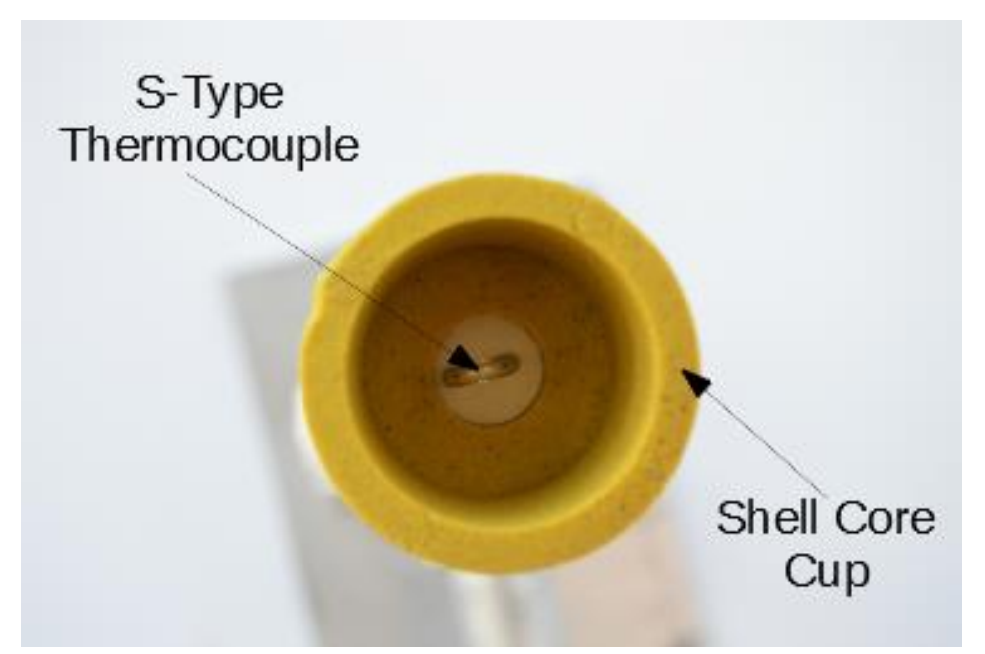

Figure 2. Typical TA cup.

Table 1. Average composition for each alloy. (wt. \%).

\begin{tabular}{ccccccccccc}
\hline Alloy & C & Si & Mn & P & S & Cr & Mo & Ni & Al & Ce $^{\mathbf{1}}$ \\
\hline 4130 & 0.32 & 0.28 & 0.45 & 0.015 & 0.013 & 0.94 & 0.25 & 0.05 & 0.12 & 0.019 \\
HY100 & 0.15 & 0.26 & 0.33 & 0.013 & 0.011 & 1.43 & 0.53 & 2.74 & 0.10 & 0.010 \\
\hline
\end{tabular}

${ }^{1}$ Cerium values are only for treated heats.

Metallographic analysis for the TA cup and inclusion specimen were as follows. Grinding using 180, 320, and 600 grit $\mathrm{SiC}$ papers occurred first. The TA cups were then etched with a 25 vol. $\% \mathrm{HNO}_{3} / 75$ vol. \% water macroetch for 4130 and a 50 vol. $\% \mathrm{HCl}$, $25 \% \mathrm{HNO}_{3}, 25$ vol. \% water etchant for HY100. Images of the resulting macrostructure were captured with a digital camera at the same focal length. Two lights were used to illuminate the sample surfaces, one with a blue filter and one with a red filter. This illumination technique improved the contrast in the digital images.

The inclusion samples underwent the same grinding process outlined for the TA cups, but they were further processed by rough polishing with $6 \mu \mathrm{m}$ and then $1 \mu \mathrm{m}$ polycrystalline diamond compounds. Final polishing employed $0.05 \mu \mathrm{m}$ alumina. A $2 \%$ Nital etched the inclusion samples for better contrast. A JEOL 5400 scanning electron microscopy (SEM) (Peabody, MA, USA) with an Oxford Instruments INCA energy dispersive spectrometer (EDS) (Concord, MA, USA) analyzed the inclusions. A $15 \mathrm{kV}$ accelerating voltage and $15 \mathrm{~mm}$ working distance were employed.

\section{Results}

\subsection{Macrostructure}

Examination of the macrostructure in the TA cups found refinement occurred in 4130 but not HY100 (Figures 3 and 4). (The large dark areas are gas porosity formed by the shell binder being burned out.) In 4130, the RE silicide (0.3 RE) and EGR (0.3 EGR) show a finer structure than the Baseline sample (Figure 3). The average grain size measured by linear intercept method was $1.5 \mathrm{~mm}$ for the Baseline, $0.9 \mathrm{~mm}$ for the RE silicide, and $0.8 \mathrm{~mm}$ for the EGR samples. However, as shown in Figure 4, the macrostructures of all three TA cups appear similar in HY100. Grain size measurements for the Baseline, RE, and EGR HY100 samples were $1.3 \mathrm{~mm}, 1.6 \mathrm{~mm}$, and $1.1 \mathrm{~mm}$, respectively. These results are consistent with previous work by the author on these steels [11,18]. While not affecting HY100, rare earth-based additions appear to refine 4130. 


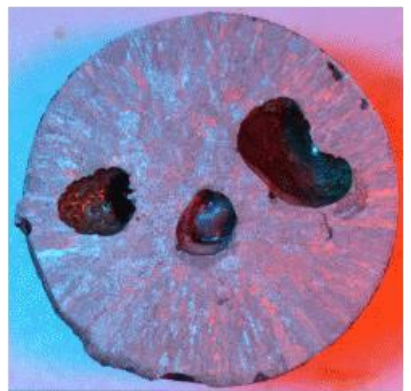

Baseline

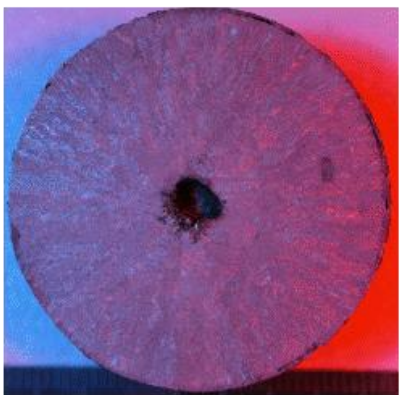

$0.3 \mathrm{RE}$

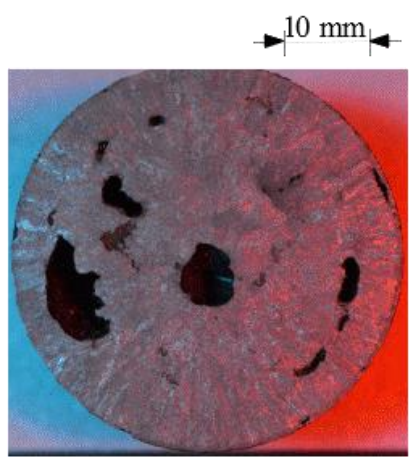

0.3 EGR

Figure 3. 4130 TA cup macrostructures.

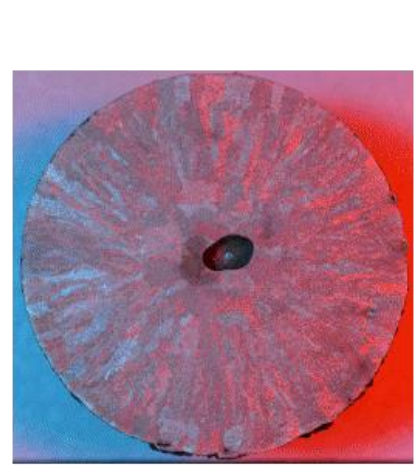

Baseline

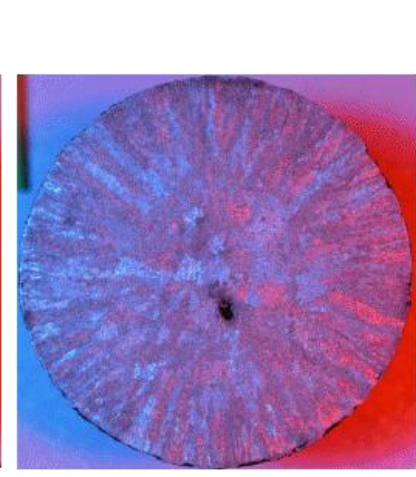

$0.3 \mathrm{RE}$

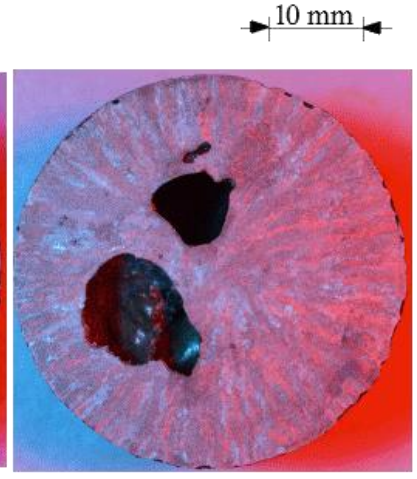

0.3 EGR

Figure 4. HY100 TA cup macrostructures.

\subsection{TA Results}

Examination of the first derivative, or cooling rate, of the TA data provides distinct peaks which are easy to identify. Liquidus identification used the built-in algorithm that finds the first time the cooling rate reaches zero; the solidus is identified as the largest peak on the curve. Peritectic identification requires manual identification since an existing algorithm has not been developed. Figures 5-7 depict the cooling curves for the 4130 heats. Unlike DSC, the solidus peaks and many of the peritectic peaks are evident. One item apparent in the treated 4130 heats was the presence of additional peaks. These peaks were identified based on Scheil calculations of the phase evolution during solidification using ThermoCalc and the TCFE9 database. The author should note that the exact phases may be misidentified since no X-ray diffraction (XRD) data could be obtained to verify the phases formed at this temperature.

Table 2 summarizes the solidification reaction temperatures from the Scheil calculations and TA measurements. The Scheil calculation for these predicted values was the same as for the solidification sequence. The liquidus for all three heats appears lower than the predicted value with the treated steels being the lowest. The lower value indicates that neither the addition of RE silicide or EGR caused heterogeneous nucleation of $\delta$-ferrite during solidification. The depression of the reaction temperature may be due to the addition of more alloying elements in the melt. The peritectic temperature of the Baseline heat matched the predicted values. However, the treated steels had peritectic reactions higher than the prediction and Baseline sample. This increase likely indicates that the RE inclusions in the melt acted as nuclei for austenite and allowed the reaction to occur at a higher temperature, which was consistent with expected results for heterogeneous nucleation [36]. The solidus for all three heats were higher than the predicted values. A higher solidus than predicted by thermodynamic software has been observed in other work and appears to be related to the original experimental data employed as the basis for a particular thermodynamic 
database $[25,26]$. The solidus temperature for the treated steels appears higher than the Baseline heat. This increase may be related to the refinement observed.

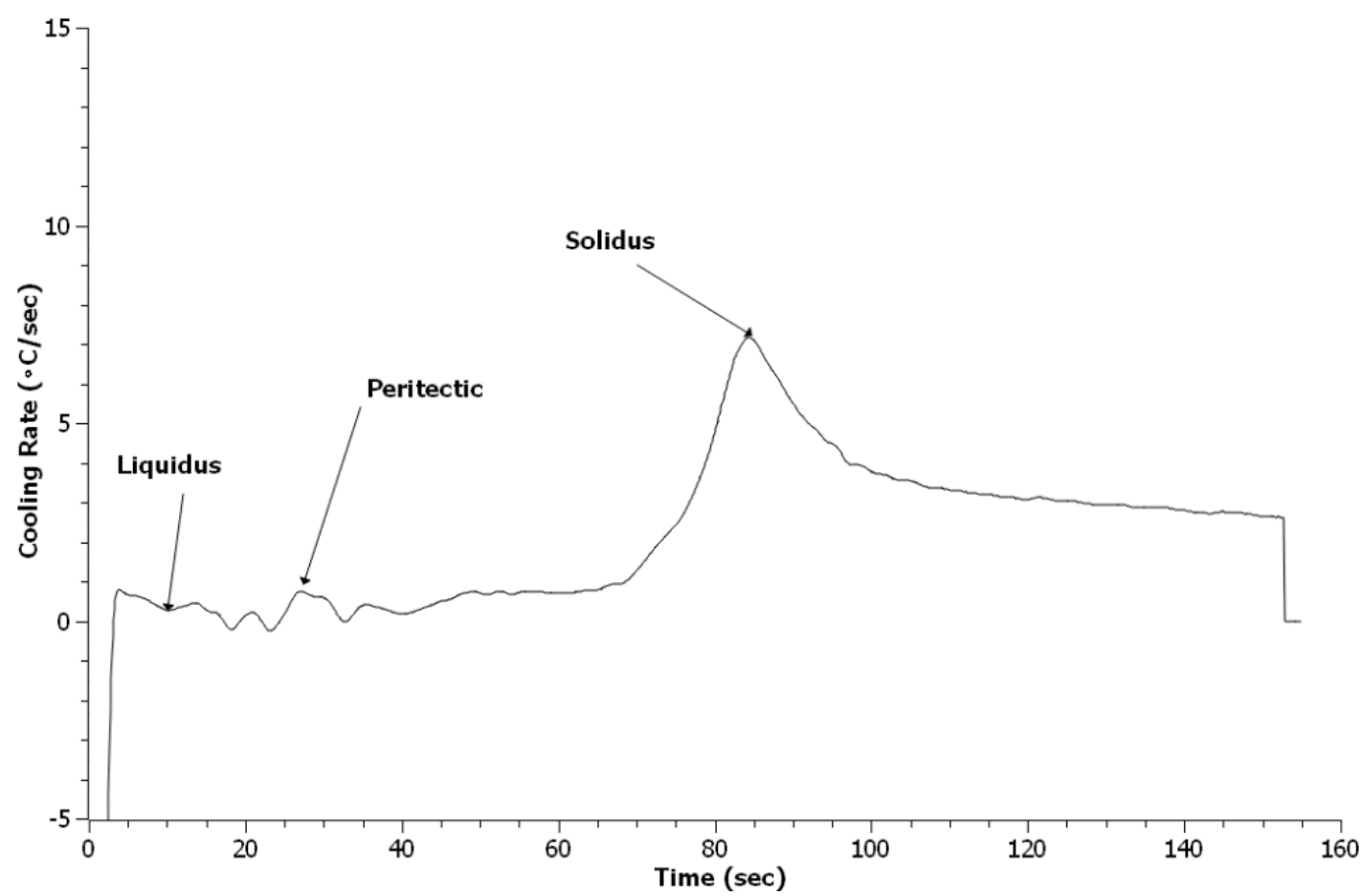

Figure 5. Cooling curve for Baseline 4130 heat.

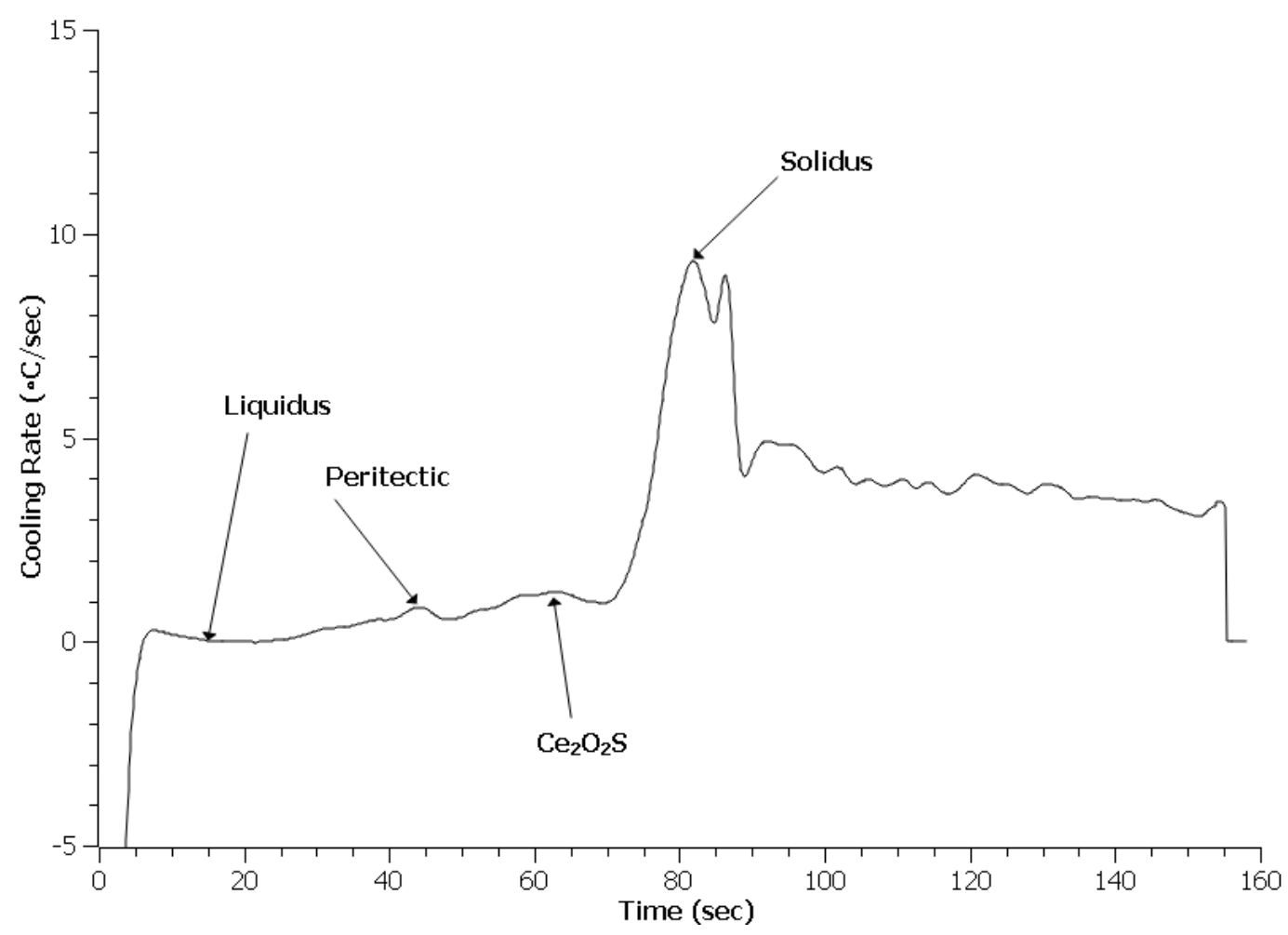

Figure 6. Cooling curve for 0.3 RE 4130 heat. 


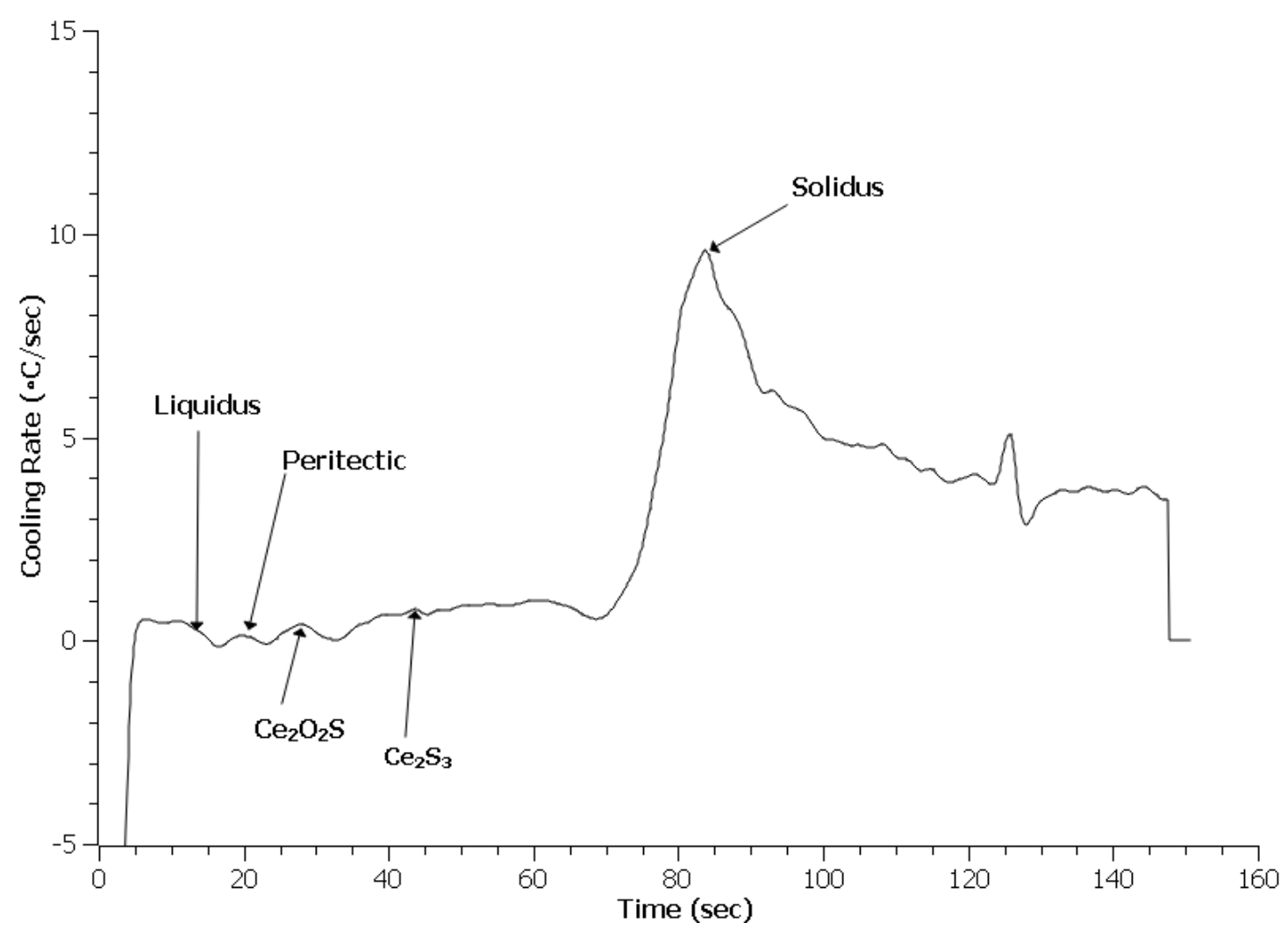

Figure 7. Cooling curve for 0.3 EGR 4130.

Table 2. Measured and predicted phase reaction temperatures for 4130 . $\left({ }^{\circ} \mathrm{C}\right)$.

\begin{tabular}{cccccc}
\hline Heat & Liquidus & Peritectic & Solidus & $\mathbf{C e}_{\mathbf{2}} \mathbf{O}_{\mathbf{2}} \mathbf{S}$ & $\mathbf{C e}_{\mathbf{2}} \mathbf{S}_{\mathbf{3}}$ \\
\hline Predicted & 1506 & 1483 & 1409 & 1463 & 1425 \\
Baseline & 1497 & 1483 & 1420 & - & - \\
0.3 RE & 1491 & 1487 & 1431 & 1475 & - \\
0.3 EGR & 1492 & 1492 & 1429 & 1491 & 1489 \\
\hline
\end{tabular}

An important difference with the HY100 cooling curves appears to be a lack of additional peaks indicative of other phase reactions as seen in Figures 8-10. This contrasts strongly with the 4130 curves. Table 3 lists the predicted and measured phase reaction temperatures. Scheil calculations did predict the formation of $\mathrm{Ce}_{2} \mathrm{O}_{2} \mathrm{~S}$ and $\mathrm{Ce}_{2} \mathrm{~S}_{3}$, but these reactions were not detected by TA. Overall, the reaction temperatures of the treated steels appear similar to the Baseline heat. The exception was the solidus of the 0.3 EGR HY100 heat. This was $30{ }^{\circ} \mathrm{C}$ lower than the other heats.

Table 3. Measured and predicted phase reaction temperatures for HY100. $\left({ }^{\circ} \mathrm{C}\right)$.

\begin{tabular}{cccccc}
\hline Heat & Liquidus & Peritectic & Solidus & $\mathbf{C e}_{\mathbf{2}} \mathbf{O}_{\mathbf{2}} \mathbf{S}$ & $\mathbf{C e}_{\mathbf{2}} \mathbf{S}_{\mathbf{3}}$ \\
\hline Predicted & 1501 & 1490 & 1390 & 1462 & 1423 \\
Baseline & 1497 & 1494 & 1434 & - & - \\
0.3 RE & 1496 & 1490 & 1430 & - & - \\
0.3 EGR & 1494 & 1492 & 1408 & - & - \\
\hline
\end{tabular}




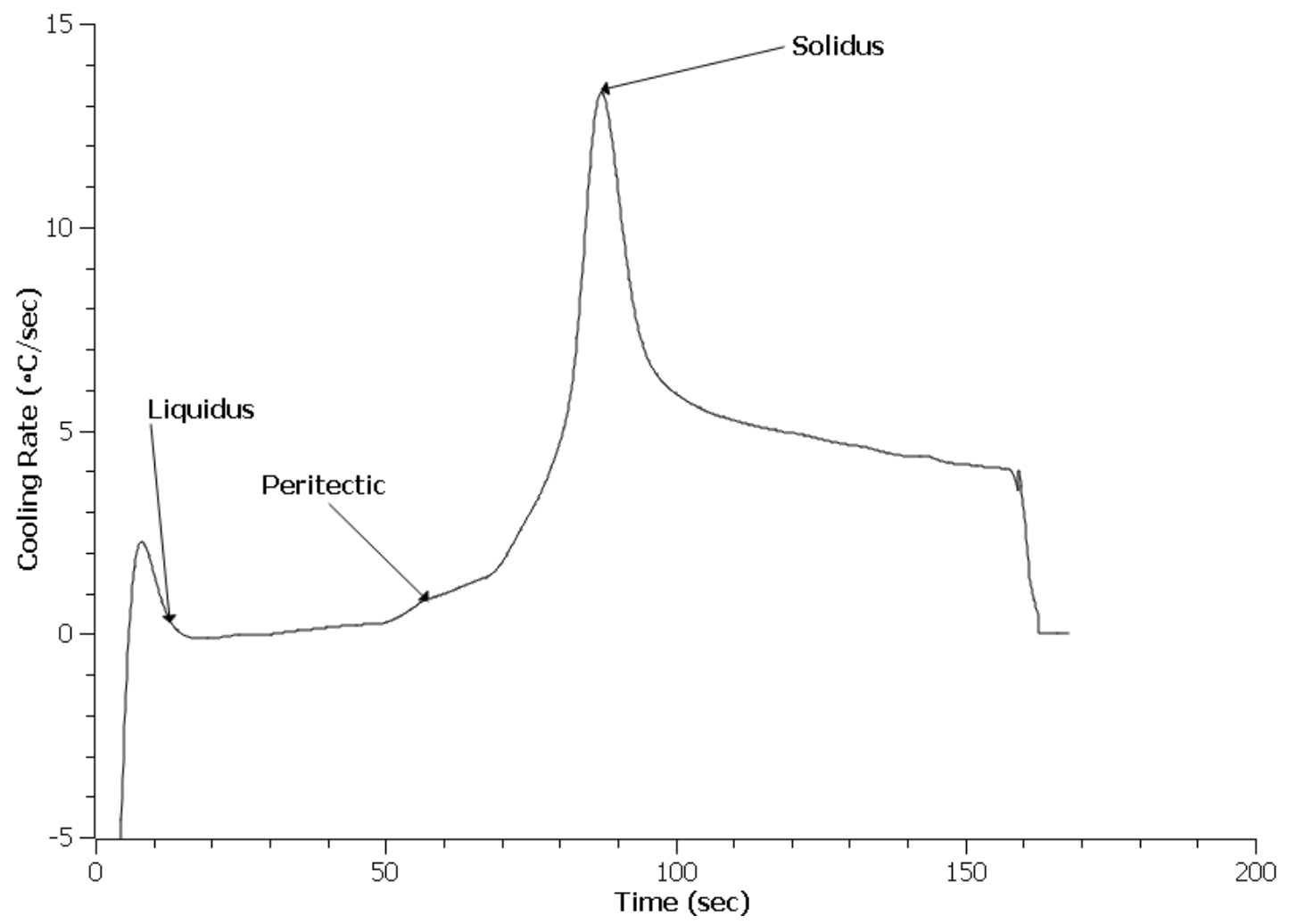

Figure 8. Cooling curve data for Baseline HY100.

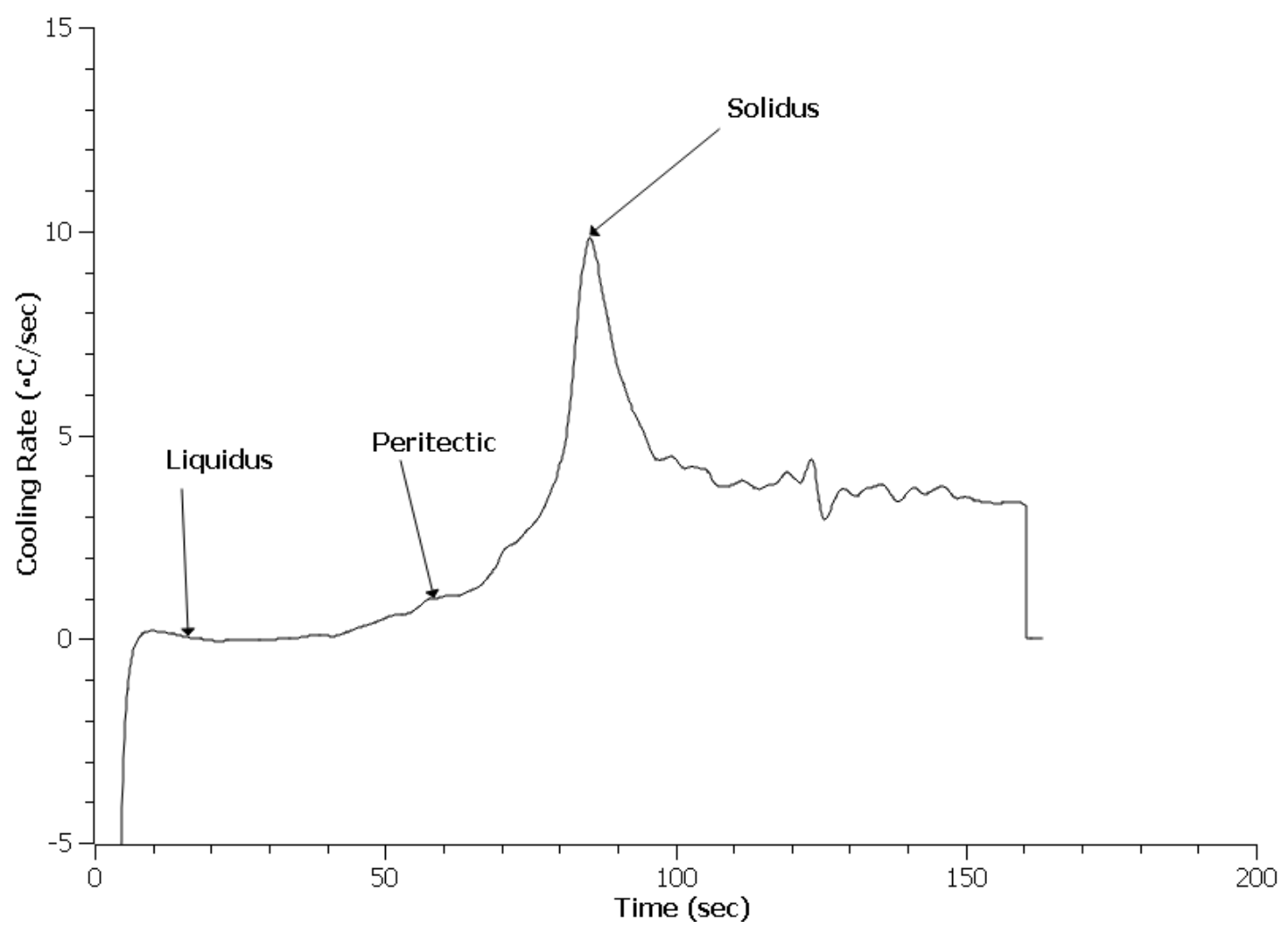

Figure 9. Cooling curve for 0.3 RE HY100. 


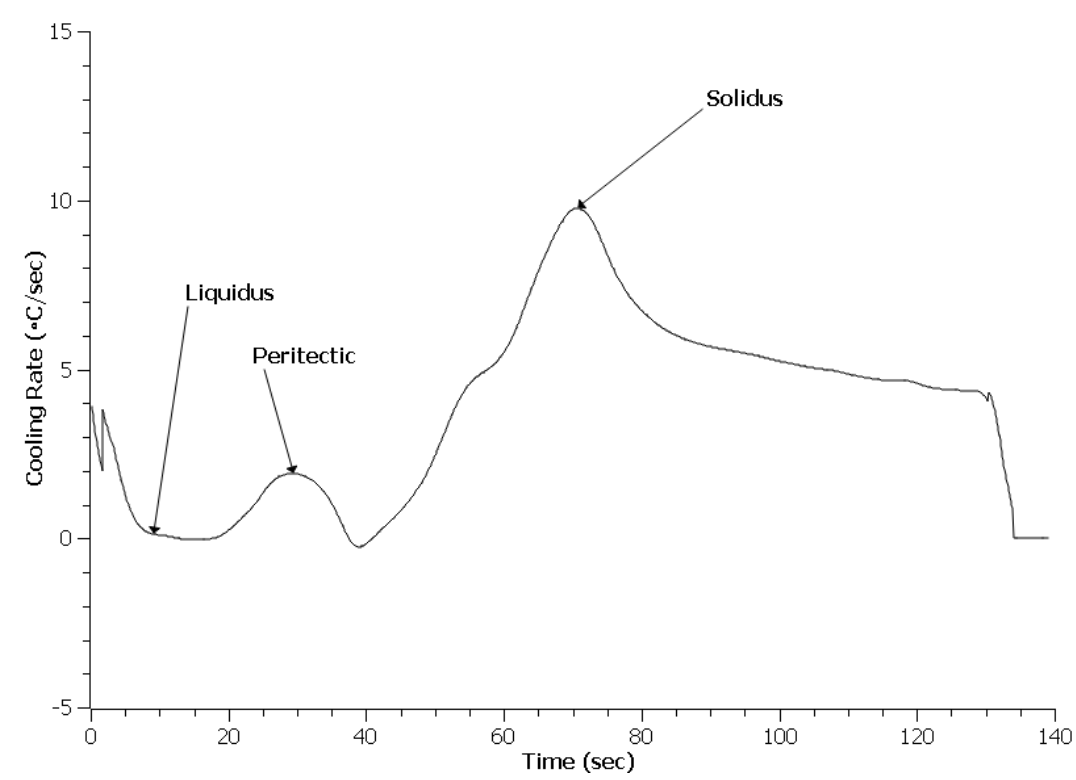

Figure 10. Cooling curve data for 0.3 EGR HY100.

\subsection{Mechanical Testing}

Figures 11-13 depict the measured mechanical properties for each heat. Error bars on all plots are $95 \%$ confidence intervals. Both treated 4130 heats had a higher yield strength and ultimate tensile strength (UTS) than the Baseline heat (Figures 11 and 12). This difference was statistically significant. Interestingly, the elongation of the Baseline and 0.3 RE heats were statistically the same while the 0.3 EGR was statistically lower. The HY100 results were mixed. The $0.3 \mathrm{RE}$ heat had a statistically lower yield strength and UTS than the Baseline. Examination of the tensile bars after testing found some porosity which likely weakened them. Previous work on HY100 observed that RE silicide and EGR produced the same properties [18]. However, the 0.3 EGR heat has higher mechanical properties overall as shown in Figures 11-13.

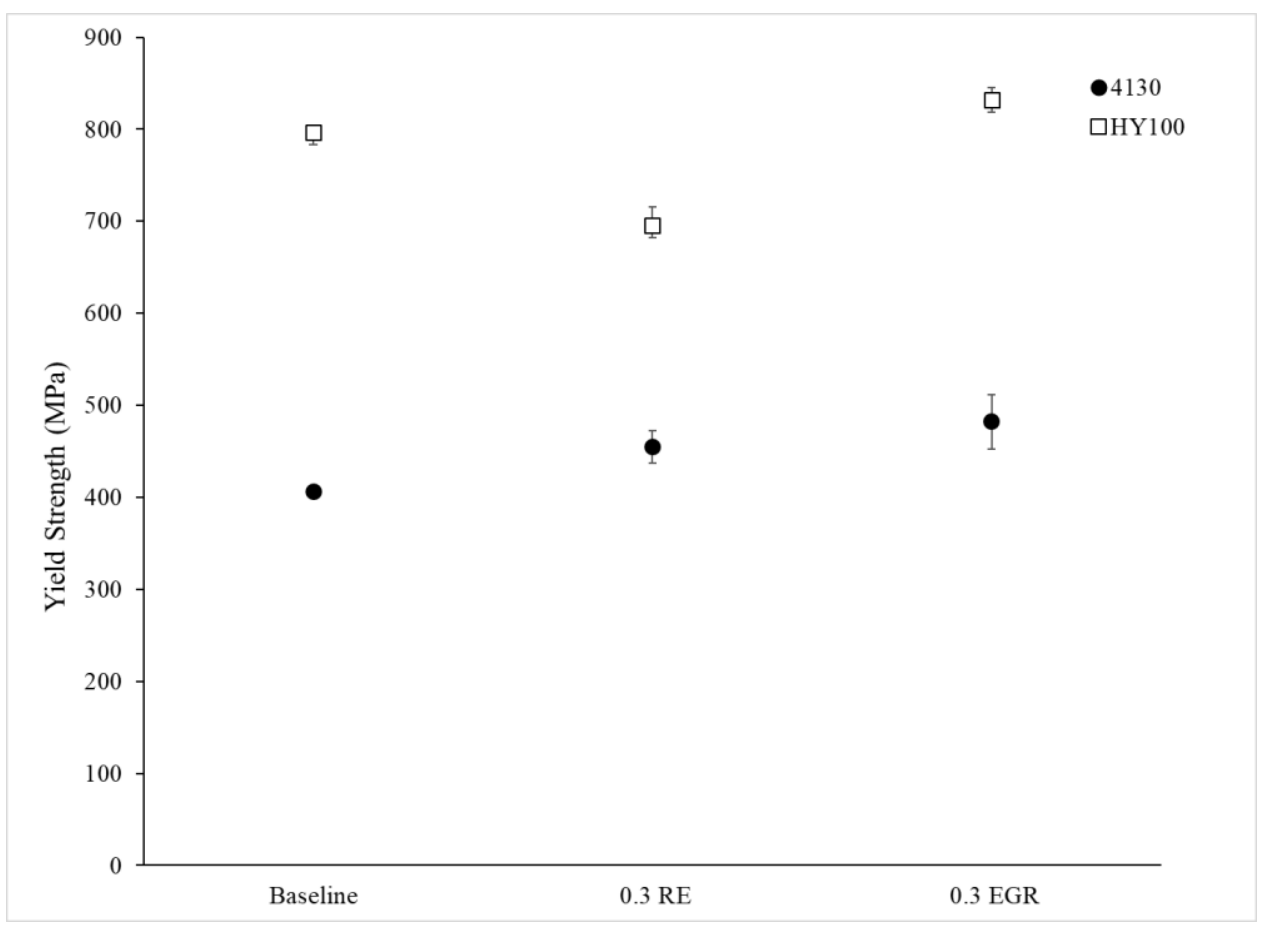

Figure 11. Yield strength for all heats. 


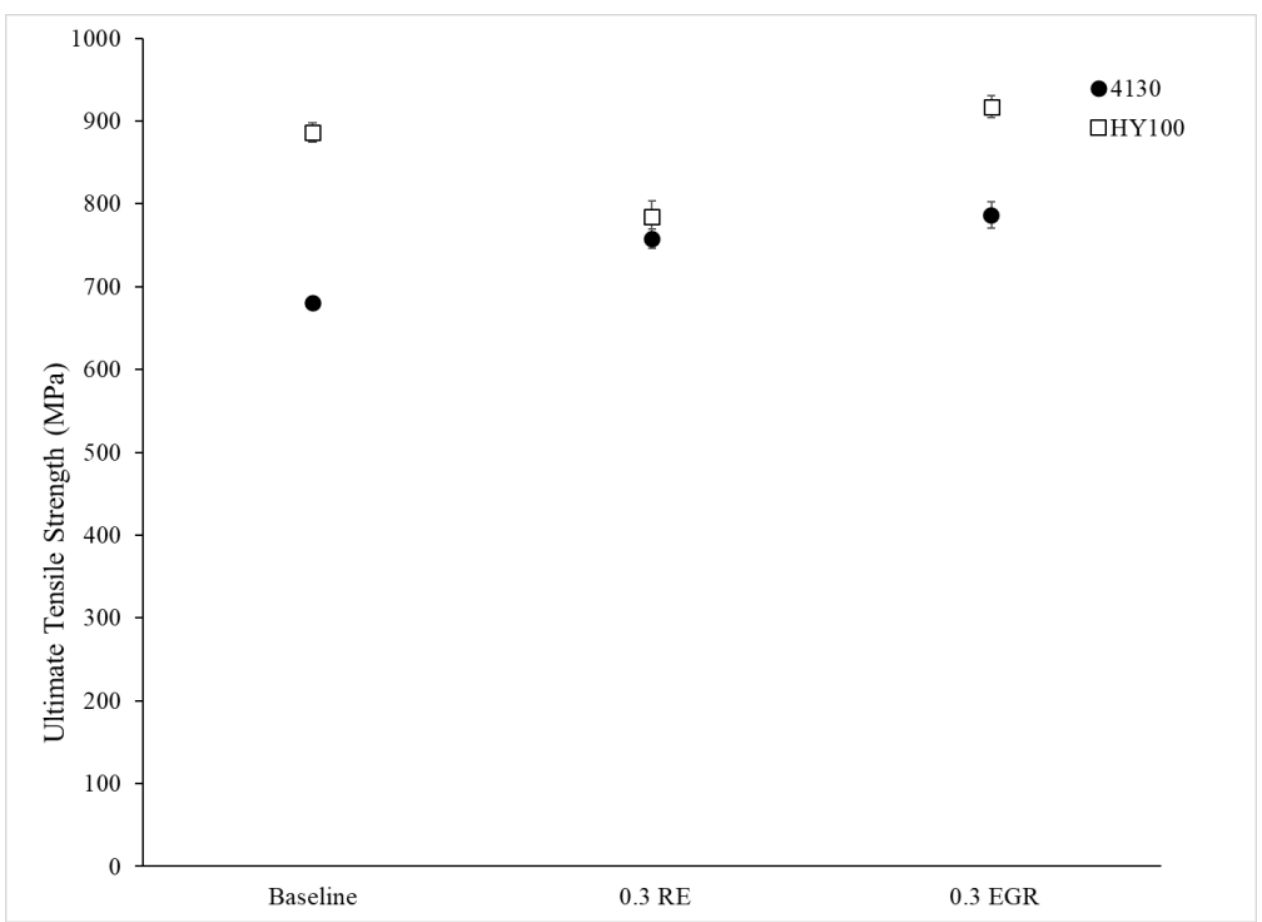

Figure 12. UTS for each heat poured.

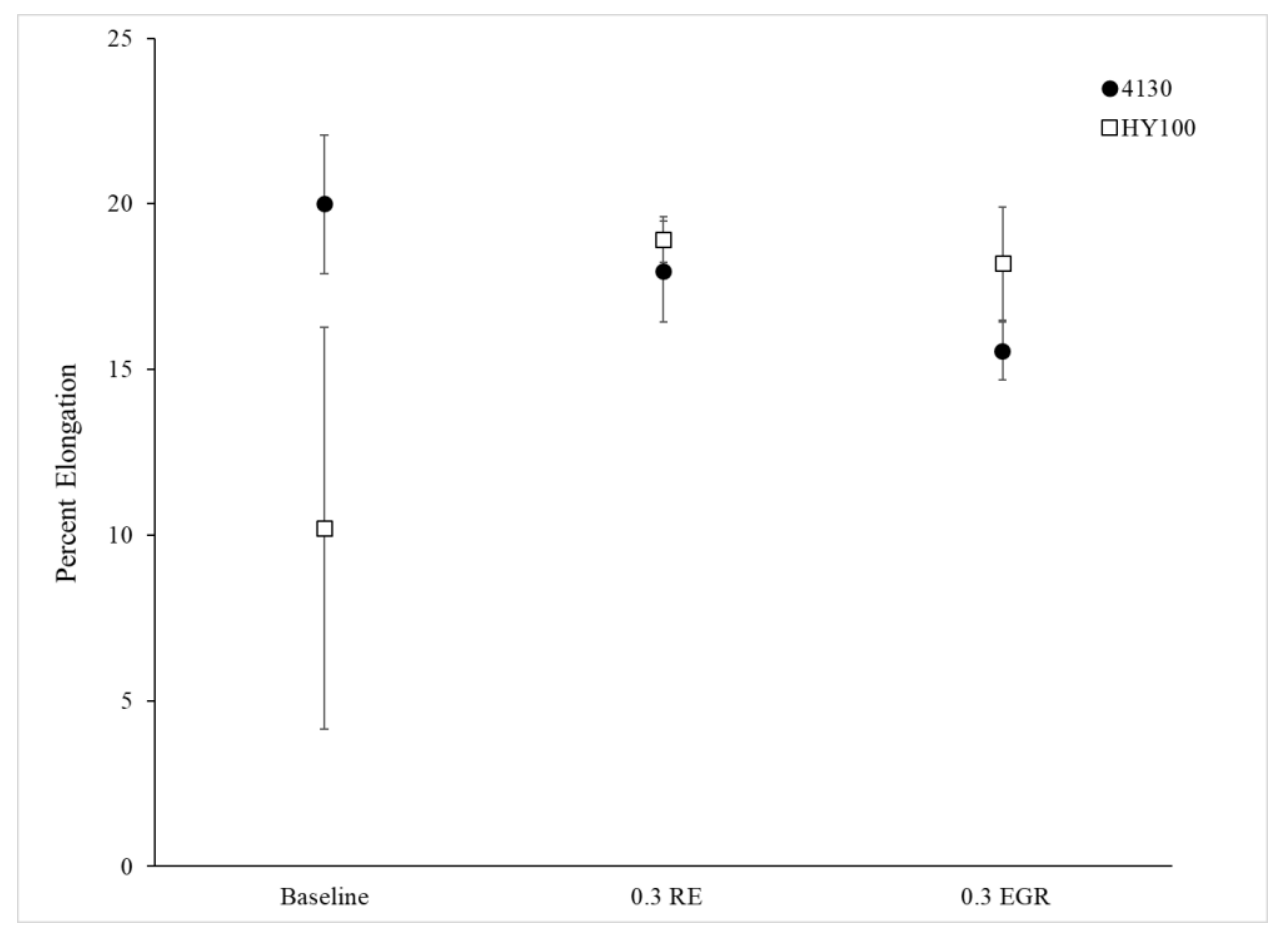

Figure 13. Elongation data for each experimental heat.

\subsection{Inclusion Anlysis}

Figures 14 and 15 provide representative inclusions from the 0.3 RE silicide treated 4130 and HY100 heats. Inclusions from the 0.3 EGR heats were similar in composition so their inclusion was omitted. Both RE oxysulfides and sulfides were discovered in all treated heats. Typical inclusions consisting of alumina, MnS, and iron-rich inclusions were found in the Baseline heats. Figure 14 depicts a typical RE oxysulfide with its composition listed in Table 4 . These types of inclusions have been observed previously by 
the author $[11,13,17,18,37]$. Similar inclusions were observed in the HY100 treated heats, but also more RE sulfide inclusions were observed (Figure 15 and Table 5). Specifically, the inclusion depicted in Figure 15 for the 0.3 RE HY100 heat appears to be composed of a modified MnS. Complex RE inclusions have been noted in prior work and this appears consistent with those observations $[11,13,18]$.

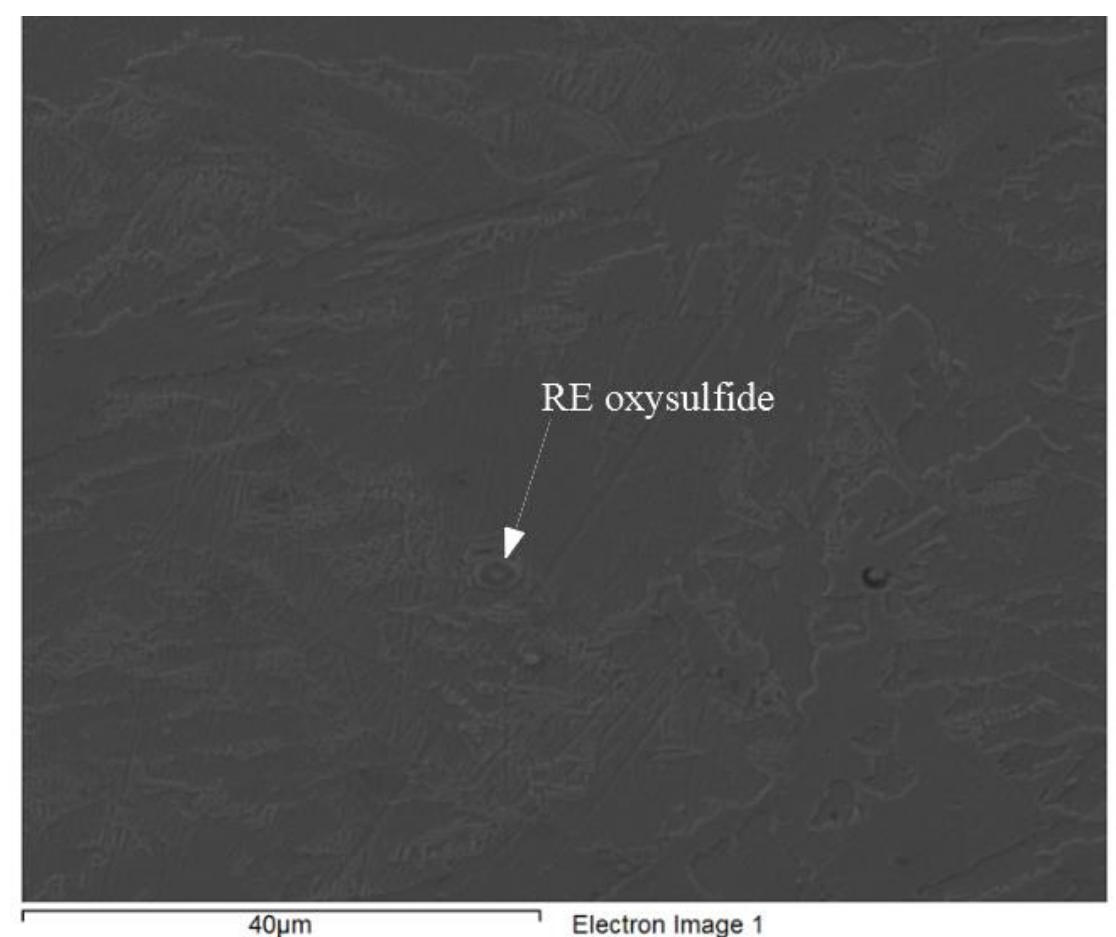

Figure 14. Typical RE oxysulfide from the 0.3 RE 4130 heat.

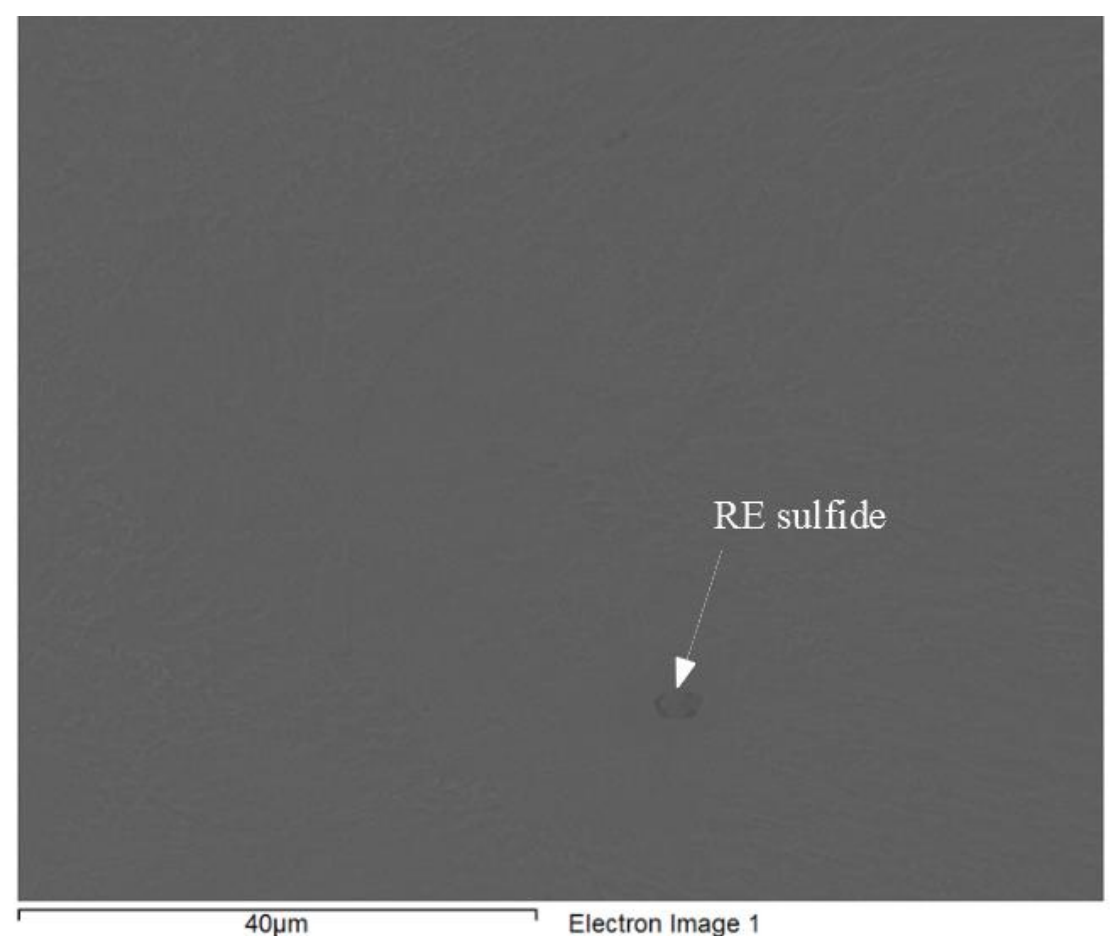

Figure 15. Typical inclusion from the 0.3 RE HY100 heat. 
Table 4. Quantitative analysis of RE oxysulfide from 0.3 RE 4130 heat. (wt. \%).

\begin{tabular}{ccccccc}
\hline Ce & La & Fe & S & Al & O & C \\
\hline 19.6 & 11.8 & 3.4 & 3.9 & 26.7 & 32.6 & 2.0 \\
\hline
\end{tabular}

Table 5. Quantitative analysis of RE oxysulfide from 0.3 RE HY100 heat. (wt. \%).

\begin{tabular}{cccccccc}
\hline Ce & La & Fe & Mn & Cr & S & Al & O \\
\hline 6.4 & 3.3 & 4.0 & 35.2 & 4.6 & 30.0 & 9.32 & 7.21 \\
\hline
\end{tabular}

The author would like to note that none of the observed inclusions had a composition similar to the $\mathrm{Ce}_{2} \mathrm{O}_{2} \mathrm{~S}$ or $\mathrm{Ce}_{2} \mathrm{~S}_{3}$ phases predicted by the Scheil calculations. These phases were predicted for both steels. However, SEM analysis found neither. Additionally, the Scheil calculations had predicted no RE compounds forming prior to freezing but did predict alumina formation. Thermodynamic data from the open literature indicates that RE compounds are as or more thermodynamically stable in molten steel as alumina [38]. Thus, not predicting any RE phases prior to solidification seems contradictory. The inclusions observed likely formed in the melt during tapping. Under the dynamic conditions that occur in tapping, the variation in inclusion composition may reflect the local chemical composition of the melt. It appears in the case of 4130 additional reactions occur. There is some evidence of a multiphase nature for the inclusion in Figure 14; this corresponds with previous observations by the author with these additions [37]. It seems likely that part of the discrepancy between the predicted and actual inclusions relates to the conditions under which the inclusions were formed.

\section{Discussion}

The change in macrostructure and TA results appear to help explain some of the difference between the 4130 and HY100 heats. The peritectic reaction temperature increased in the RE silicide and EGR treated 4130 heats but not the HY100. This increase would occur if the observed RE oxysulfide inclusions acted as heterogeneous nuclei. The presence of nuclei in the melt reduces the energy barrier necessary to initiate the solid phase [36]. A reduced energy barrier allows the reaction to occur at a higher temperature than the normal, matching the results in the TA data. The lack of peritectic reaction movement in the HY100 heats indicates that the observed inclusions did not act as heterogeneous nuclei. Furthermore, the presence of similar inclusions in the HY100 heats supports the theory that they are formed in the melt during tapping.

The lack of similar refinement performance between alloys remains unexplained by the current results. A possible explanation is related to the solidification sequence. Previous work by the author in plain carbon steels found that refining response to RE additions improved as the portion of the freezing range occupied by austenite increased [13]. Figure 16 depicts the Scheil calculation results for 4130 while Figure 17 illustrates the HY100 predications. The 4130 undergoes the peritectic reaction at approximately 0.55 into the freezing range, much later than the 0.38 of HY100. Thus, HY100 would be expected to have a better response to the RE additions. Other calculations show that the presence of RE elements in the alloy do not appear to affect the peritectic reaction temperature or mass fraction according to Thermo-Calc $\odot$. It appears the point at which the peritectic reaction for HY100 occurs does not explain the refinement difference.

Another explanation may involve the difference in alloying element content between the alloys. HY100 contains more Ni than 4130, 2.7 wt. \% verses 0.05 wt. \%. Nickel substitutes into the austenite lattice and actually decreases the size of the unit cell [39]. The resulting decrease in lattice parameter would change the lattice misfit between the austenite and RE inclusions. For instance, $\mathrm{Ce}_{2} \mathrm{O}_{3}$ has a lattice parameter of $0.389 \mathrm{~nm}$ [40]. Dyson and Holmes developed a regression equation for predicting the lattice parameter of austenite based on composition: 


$$
\begin{gathered}
\mathrm{a}_{\mathrm{o}}=0.3578+0.0330 \mathrm{C}+0.00095 \mathrm{Mn}-0.0002 \mathrm{Ni}+0.0006 \mathrm{Cr}+ \\
0.0220 \mathrm{~N}+0.0056 \mathrm{Al}-0.0004 \mathrm{Co}+0.0015 \mathrm{Cu}+0.0031 \mathrm{Mo}+0.0051 \mathrm{Nb}+ \\
0.0039 \mathrm{Ti}+0.0018 \mathrm{~V}+0.0018 \mathrm{~W}
\end{gathered}
$$

where $a_{o}$ is the lattice parameter (nm), and the elements are in wt. \% [39]. Using Equation (1) to estimate the lattice parameter in each steel gives the following: for HY100 $\mathrm{a}_{\mathrm{O}}=0.3584 \mathrm{~nm}$ and for $4130 \mathrm{a}_{\mathrm{o}}=0.3590 \mathrm{~nm}$. The predicted lattice disregistry for HY100 and 4130 are $8.5 \%$ and $8.4 \%$, respectively, practically identical. Furthermore, previous work indicating a significant effect on properties in the Q\&T condition for HY100 would confirm that the observed RE inclusions match austenite and can act as nuclei. Thus, it would appear lattice parameter differences are not the cause of the refining behavior difference.

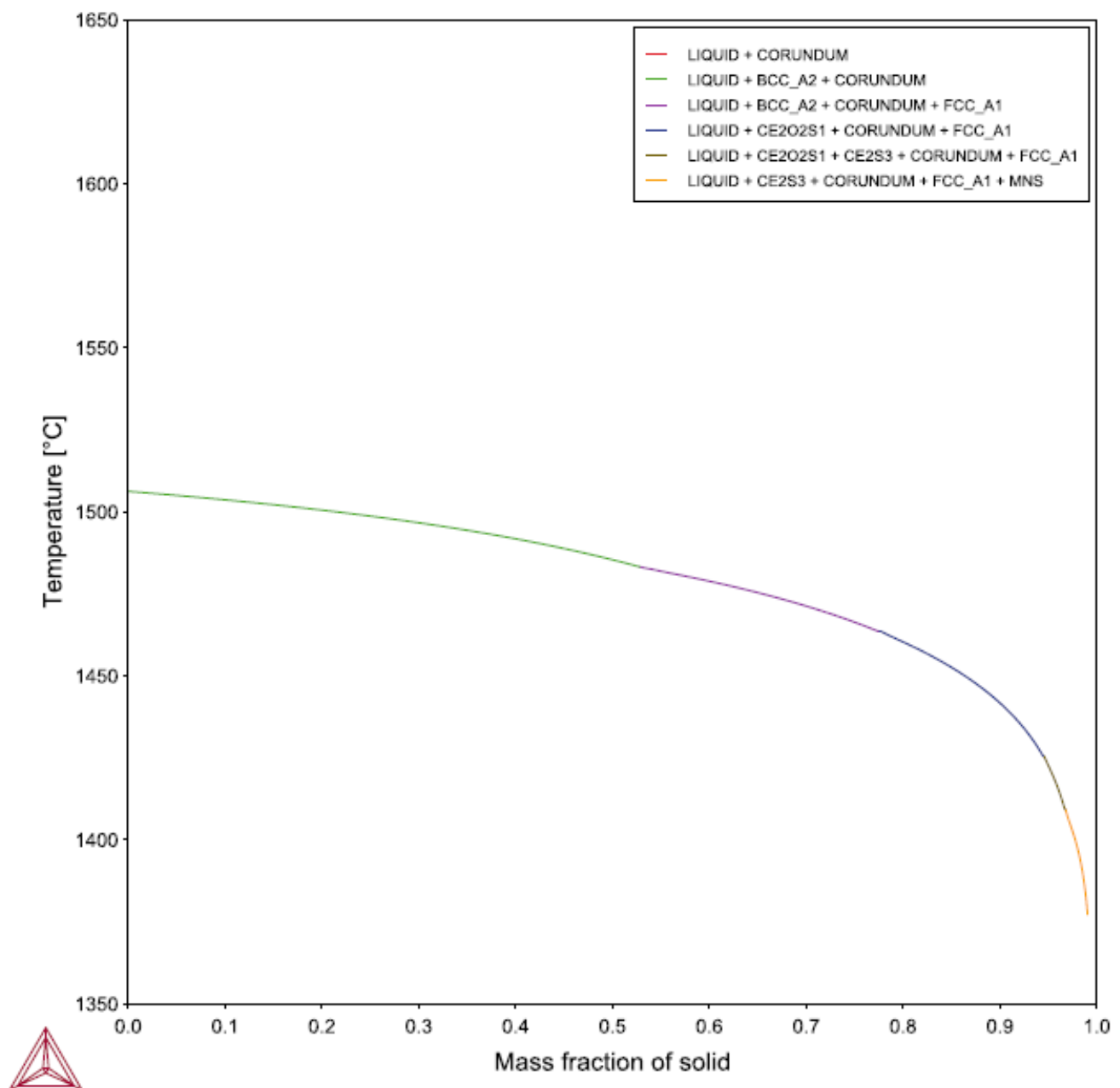

Figure 16. Scheil calculations results for 4130.

Despite the lack of significant difference in lattice parameters, the nickel content may still explain the differing refinement response. As stated earlier, HY100 has a much higher nickel content. Nickel is a substitutional element and austenite stabilizer. Substitutional elements are known to strongly segregate during solidification [41]. Nickel atoms would build up at the dendrite surface during growth. The segregation of a strong austenite stabilizing alloying element at the interface may provide a strong driving force for the formation of austenite and be the cause for the earlier occurrence of the peritectic when compared to 4130. Calculations on nickel segregation in ThermoCalc $\odot$ using the TCFE9 database and composition from Table 1 present a continual increase in the nickel content until $1490^{\circ} \mathrm{C}$ where there is a sudden drop as seen in Figure 18. This drop corresponds to 
the predicted peritectic temperature, which was verified by the experimental TA data for this alloy. The rapid incorporation of nickel following the peritectic temperature supports the theory that the alloy is rapidly forming austenite which has the face centered cubic (FCC) structure of nickel. The driving force for austenite formation due to the segregation of nickel may be larger than the decrease in the energy barrier provided by the RE inclusions present in the treated alloy. The locally high nickel content next to existing dendrites may strongly favor austenite formation at that location. Thus, the alloy does not appear to use the inclusion nucleation sites. RE inclusions floating in the melt would not necessarily already be in the high nickel content regions and thus the local environment they are in has a lower driving force for austenite.

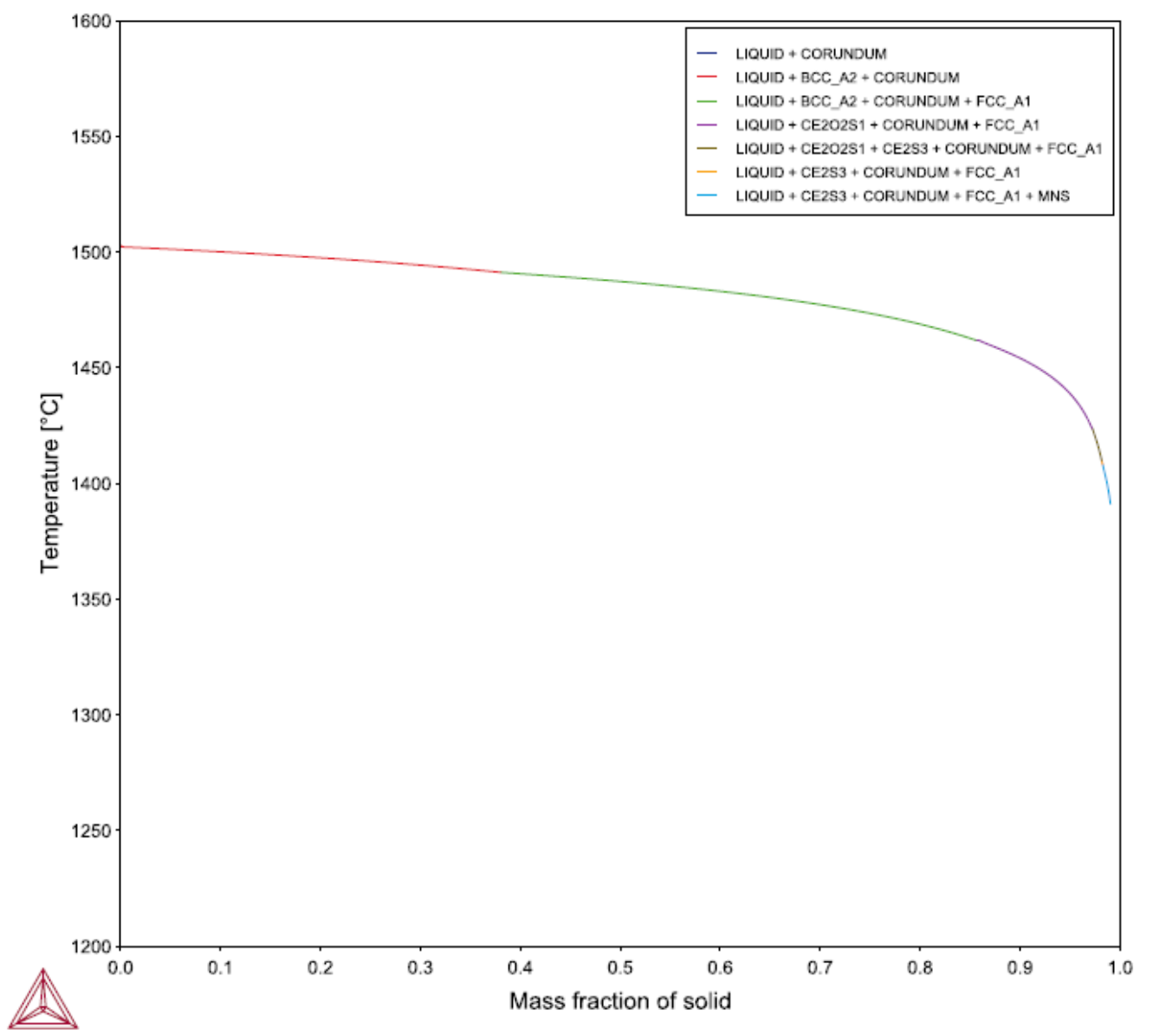

Figure 17. Scheil predictions for HY100.

Assuming the nickel segregation theory presented in this paper were correct, it would appear efforts for grain refining HY100 should focus on effective $\delta$-ferrite nuclei. Introducing effective $\delta$-ferrite nuclei would increase the number of dendrites and cause a decrease in grain size. $\mathrm{TiC}$ and $\mathrm{TiN}$ particles currently provide the most promising results and have been examined by the author using similar techniques [42]. Considering that HY100 has only responded to refinement via this route also supports the nickel segregation theory.

Additionally, supporting this theory is the fact that 4130 contains fewer austenite stabilizing elements. This may be why RE inclusions cause refinement in this alloy. Macrostructure images demonstrated that RE additions result in refinement during solidification and mechanical properties improve. TA data indicates that this refinement corresponds to an increase in the peritectic temperature. This increase indicates easier formation of austenite than normal in the alloy. The RE inclusions acting as heterogeneous nuclei is consistent with this observation. Heterogeneous nuclei provide an existing solid surface for atoms from the liquid to bond with. Without an effective solid acting as a nucleus, atoms from the 
liquid must create a solid embryo which requires overcoming the bulk and surface energies associated with a solid [41]. This reduction in energy barrier enables the phase reaction to occur at a higher temperature because less undercooling was needed to initiate it. Thus, the phase reaction temperature increases. Since 4130 contains fewer austenite stabilizing elements that segregate near the dendrites, it appears the energy barrier reduction provided by the presence of heterogeneous nuclei favored the formation of austenite.

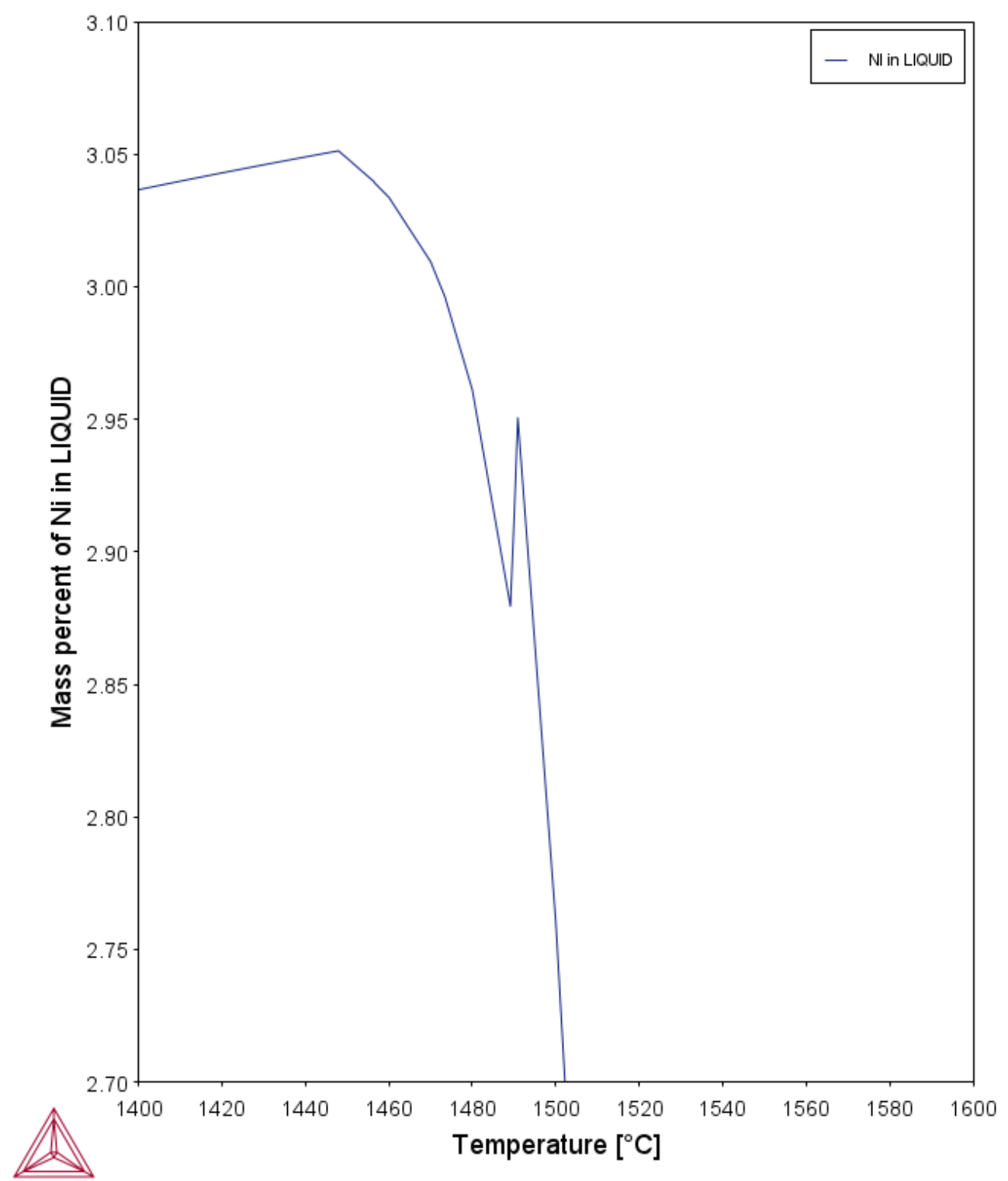

Figure 18. Predicted nickel segregation in HY100 during solidification.

The difference in behavior between the 4130 and HY100 heats revealed that alloy steels may have more complex responses to refinement. The author's work in plain carbon steels found more consistent response to RE silicide and EGR additions [13]. A mixed response to refinement has been observed in other alloy steels. Aravola et al. examined a dual phase $\mathrm{Cr}-\mathrm{Ni}$ stainless steel that had primary dendrites of $\delta$-ferrite and austenite [43]. These authors noted some refinement of the alloy but no significant change in the columnarto-equiaxed transition as expected. This alloy contained significant amounts of nickel as well. Work in other fully austenitic alloys not containing nickel have responded well to RE based grain refinement. Bartlett and Avila found cerium additions to a FeMnAl alloy resulted in a refined structure [10]. These experimental results, combined with the work 
in this paper, hint at a complex interaction between solidification response and alloying elements which is not present in plain carbon steels. The poor refinement response for high nickel alloys may reflect an overall issue in these alloys or a simple coincidence. Continued experimentation will be necessary to determine which is the case.

\section{Conclusions}

Two different alloy steels were treated with rare earth silicide and EGR. In the 4130 heats, refinement was observed in the macrostructure, mechanical properties improved, and the peritectic temperature increased. The HY100 heats showed no refinement in the macrostructure or change in the liquidus or peritectic. Some changes in the solidus were detected that may correspond to the formation of low melting point phases late in solidification. The divergence in grain refining response were similar to previous work in these alloys. Rare earth inclusions were found in all the treated alloys. There did not appear to be a significant difference in their composition between the two alloys. Their composition did differ from thermodynamic predictions made.

The response to rare earth-based refinement in 4130 seemed to correlate to the increase in the peritectic reaction temperature. The higher peritectic temperature observed indicates that the inclusions acted as heterogeneous nuclei for austenite. By promoting austenite formation early enough in the freezing process, the steel formed more dendrites that caused a finer dendrite arm spacing. The finer structure improved mechanical properties.

The lack of response to the rare earth additions in HY100 appears to be related to its higher nickel content. Segregation calculations showed that the nickel content of the liquid increases until the peritectic reaction occurs, where it rapidly drops. Nickel stabilizes austenite so it appears that segregation of this element provides a strong driving force for austenite formation. That driving force may be larger than the reduction in energy barrier provided by the presence of RE inclusions in the melt. Hence, their ineffectiveness in refining HY100.

Funding: This research was funded by the Office of Naval Research under award number N000141712766. The APC was funded by MDPI.

Institutional Review Board Statement: Not applicable.

Informed Consent Statement: Not applicable.

Data Availability Statement: Data available upon request from author.

Acknowledgments: The author wishes to thank the following people for their efforts. Isaak Portice, James Rye, and Anthony Pitera assisted in conducting the experiments and sample preparation. The continual discussion of single thermocouple thermal analysis with David Sparkman from MeltLab Systems helps understanding the practical and theoretical limits of this technique. Elkem's donation of EGR is also greatly appreciated. FOSECO's general support through various foundry supplies plays an important role in support all the work at SVSU. Jennie Tuttle also provided her expert editing and grammar experience in reviewing this manuscript's first draft.

Conflicts of Interest: The author declares no conflict of interest.

\section{References}

1. Speer, J.; De Cooman, B. Fundamentals of Steel Product Physical Metallurgy, 1st ed.; Association of Iron \& Steel Technology: Pittsburg, PA, USA, 2011; ISBN 978-1-935117-16-2.

2. Bramfitt, B.L. Effect of Carbide and Nitride Additions on the Heterogeneous Nucleation Behavior of Liquid Iron. Met. Trans. 1970, 1, 1987-1995. [CrossRef]

3. Zhang, M.; Kelly, P.; Easton, M.; Taylor, J. Crystallographic Study of Grain Refinement in Aluminum Alloys Using the Edge-toEdge Matching Model. Acta Mater. 2005, 53, 1427-1438. [CrossRef]

4. Kelly, P.; Zhang, M.-X. Edge-to-Edge Matching-A New Approach to the Morphology and Crystallography of Precipitates. Mater. Forum 1999, 23, 41-62.

5. Zhang, M.-X.; Kelly, P.M. Edge-to-Edge Matching Model for Predicting Orientation Relationships and Habit Planes-the Improvements. Scr. Mater. 2005, 52, 963-968. [CrossRef] 
6. $\quad$ van der Eijk, C.; Walmsley, J. Grain Refinement of Fully Austenitic Stainless Steels Using a Fe-Cr-Si-Ce Master Alloy. In Proceedings of the 59th Electric Furnace and 19th Process Technology Conferences, Phoenix, Arizona, 11-14 November 2001; pp. 51-60.

7. Wang, L.; Lin, Q.; Yue, L.; Liu, L.; Guo, F.; Wang, F. Study of Application of Rare Earth Elements in Advanced Low Alloy Steels. J. Alloys Compd. 2008, 451, 534-537. [CrossRef]

8. Tang, Z.; Zhang, X. Effect of Rare Earth on 30CrMnSi Steel Investment Castings Cracking. Adv. Mater. Res. 2011, 160-162, 692-697. [CrossRef]

9. Ji, Y.; Guo, H.; Zheng, X.; Jin, Z.; Ren, H. Influence of Rare Earth on Microstructure of 20MnCrNi2Mo Wear-Resistant Cast Steel. Adv. Mater. Res. 2013, 652-654, 934-937. [CrossRef]

10. Bartlett, L.N.; Avila, B.R. Grain Refinement in Lightweight Advanced High-Strength Steel Castings. Int. J. Met. 2016, 10, 401-420. [CrossRef]

11. Tuttle, R.B. Effect of Rare Earth Additions on 4130. In Proceedings of the AISTech 2017, Nashville, TN, USA, 8 May 2017; AIST: Nashville, TN, USA, 2017; pp. 3005-30015.

12. Tuttle, R.B. Effect of RE Oxide Grain Refinement on the Heat Treated Properties of 1030 Steel. In Proceedings of the AISTech, Indianapolis, IN, USA, 5-8 May 2014; pp. 1619-1630.

13. Tuttle, R.B. Effect of Austenite Fraction on Rare Earth Grain Refinement. In Proceedings of the 121st Metalcasting Congress, Milwaukee, WI, USA, 25 April 2017; American Foundry Society: Milwaukee, WI, USA, 2017.

14. Mizumoto, M.; Sasaki, S.; Ohgai, T.; Kagawa, A. Development of New Additive for Grain Refinement of Austenitic Stainless Steel. Int. J. Cast Met. Res. 2008, 21, 49-55. [CrossRef]

15. Haakosen, J.; Solberg, J.; Klevan, O.; van der Eijk, C. Grain Refinement of Austenitic Manganese Steels. In Proceedings of the AISTech 2011 Proceedings, Indianapolis, IN, USA, 2-5 May 2011; Volume II, pp. 763-771.

16. Tuttle, R.B. Grain Refinement in Plain Carbon Steels. Trans. Am. Foundry Soc. 2010, 118, 425-435.

17. Tuttle, R. Effect of Rare Earth Oxides in Plain Carbon Steels. In Proceedings of the AISTech, Pittsburg, PA, USA, 6-9 May 2013; pp. 1085-1093.

18. Tuttle, R.B. Influence of Rare Earth Additions on the Structure of HY100. In Proceedings of the 122 Metalcasting Congress, Fort Worth, TX, USA, 4 May 2018.

19. Han, Z.; Liu, J.; He, Y.; Li, K.; Ji, Y.; Liu, J. Determination of the Liquidus and Solidus Temperatures of FeCrAl Stainless Steel. Int. J. Miner. Met. Mater 2015, 22, 1141-1148. [CrossRef]

20. Wielgosz, E.; Kargul, T. Differential Scanning Calorimetry Study of Peritectic Steel Grades. J. Therm. Anal. Calorim. 2015, 119, 1547-1553. [CrossRef]

21. Sun, S.-H.; Zhao, A.-M.; Ding, R.; Li, X.-G. Effect of Heat Treatment on Microstructure and Mechanical Properties of Quenching and Partitioning Steel. Acta Metall. Sin. 2018, 31, 216-224. [CrossRef]

22. Gojić, M.; Sućeska, M.; Rajić, M. Thermal Analysis of Low Alloy Cr-Mo Steel. J. Therm. Anal. Calorim. 2004, 75, 947-956. [CrossRef]

23. Stefanescu, D.M. Thermal Analysis-Theory and Applications in Metalcasting. Int. J. Met. 2015, 9, 7-22. [CrossRef]

24. Boettinger, W.J.; Kattner, U.R.; Moon, K.; Perepezko, J. NIST Recommended Practice Guide: DTA and Heat-Flux DSC Measurements of Alloy Melting and Freezing; NIST: Gaithersburg, MD, USA, 2006.

25. Kapadia, H.A.; Tuttle, R.B. A System for the Thermal Analysis of Steels. In Proceedings of the 123rd Metalcasting Congress, Atlanta, GA, USA, 27 April 2019.

26. Tuttle, R.B. Peritectic Determination by a Melt Deck Thermal Analysis System. Arch. Foundry Eng. 2019, 19, 83-88. [CrossRef]

27. Binczyk, F.; Cwajna, J.; Gradon, P. ATD and DSC Analysis of IN-713C and ZhS6U-VI Superalloys. Arch. Foundry Eng. 2017, 17, 13-16. [CrossRef]

28. Dojka, M.; Dojka, R.; Studnicki, A. Development of a New ATD-P Tester for Hard Wear Resistant Materials. Arch. Foundry Eng. 2017, 17. [CrossRef]

29. Abraham, S.; Bodnar, R.; Lonnqvist, J.; Shahbazian, F.; Lagerstedt, A.; Andersson, M. Investigation of Peritectic Behavior of Steel Using a Thermal Analysis Technique. Metall. Mater. Trans. A 2019, 50, 2259-2271. [CrossRef]

30. Kapadia, H.A.; Tuttle, R.B. A System for the Thermal Analysis of Steels. Trans. Am. Foundry Soc. 2019, 127, 357-369.

31. Tuttle, R.B. Thermal Analysis of Rare Earth Additions to HY100. J. Mater. Eng. Perform. 2019, 28, 2707-2715. [CrossRef]

32. Tuttle, R.; Kapadia, H.A. Thermal Analysis of Rare Earth Grain Refined 4130. Int. J. Met. 2018, 13, 273-285. [CrossRef]

33. Tuttle, R.B. Thermal Analysis and Properties of 1030 with Mg \& Ti Additions. Trans. Am. Foundry Soc. 2020, 128, $241-252$.

34. Tuttle, R. Thermal Analysis Experiments in Titanium and Magnesium Additions to 4130 Steel. J. Mater. Eng. Perform. 2020, 29, 5913-5922. [CrossRef]

35. Tuttle, R.B. Study of Rare Earth Additions Effect on the Solidification and Properties of 4130 Steel. J. Mater. Eng. Perform. 2019, 28, 6720-6727. [CrossRef]

36. Gruzleski, J.E. Microstructure Development During Metalcasting; American Foundrymen's Society, Inc.: Schaumburg, IL, USA, 2000; ISBN 978-0-87433-204-9.

37. Tuttle, R.; Song, K. Characterization of Rare Earth Inclusions from Cast 1010 Steel. Int. J. Met. 2015, 9, 23-31. [CrossRef]

38. McLean, A.; Lu, S.K. Thermodynamic Behavior of Rare Earth Elements in Molten Steel. Met. Mater. 1974, 8, 452-457.

39. Dyson, D.J.; Holmes, B. Effect of Alloying Additions on the Lattice Parameter of Austenite. J. Iron Steel Inst. Lond. 1970, 208, 469-474. 
40. Inorganic Material Database (AtomWork). Available online: http:/ / crystdb.nims.go.jp/index_en.html (accessed on 1 July 2016).

41. Stefanescu, D. Science and Engineering of Casting Solidification, 3rd ed.; Springer: New York, NY, USA, 2015; ISBN 978-3-319-15692-7.

42. Tuttle, R.B. Effect of Magnesium and Titanium on the Mechanical Properties of HY100. In Proceedings of the AISTech 2020, Cleveland, OH, USA, 31 August-3 September 2020; AIST: Pittsburg, PA, USA, 2020.

43. Arvola, D.; O'Malley, R.; Lekakh, S.N.; Bartlett, L.N. Effect of Phase Solidification Sequence in Stainless Steel on Grain Refining Efficiency. In Proceedings of the AISTech 2018 Proceedings; AIST: Philadelphia, PA, USA, 2018; Volume III, pp. 2651-2662. 